\title{
Can pycnogenol prevent cisplatin-induced damage in uterus and ovaries?
}

Can Turkler ${ }^{1}$, Tunay Kiremitlii ${ }^{1}$, Taylan Onat ${ }^{2}$, Engin Yildirim ${ }^{3}$, Gulce N. Yazici ${ }^{4}$, Renad Mammadov ${ }^{5}$, Mukadder Sunar ${ }^{6}$

\author{
'Department of Gynecology and Obstetrics, Faculty of Medicine, Erzincan Binali \\ Yıldırım University, Erzincan, Turkey \\ 2Department of Gynecology and Obstetrics, Faculty of Medicine, Bozok University, \\ Yozgat, Turkey \\ ${ }^{3}$ Department of Gynecology and Obstetrics, Faculty of Medicine, Hitit University, \\ Corum, Turkey \\ ${ }^{4}$ Department of Histology and Embryology, Faculty of Medicine, Erzincan Binali \\ Yıldırım University, Erzincan, Turkey \\ ${ }^{5}$ Department of Pharmacology, Faculty of Medicine, Erzincan Binali Yıldırım University, \\ Erzincan, Turkey \\ ${ }^{6}$ Department of Anatomy, Faculty of Medicine, Erzincan Binali Yıldırım University, \\ Erzincan, Turkey
}

Submitted: 14 February 2019; Accepted: 5 May 2019

Online publication: 6 December 2019

Arch Med Sci 2022; 18 (5): 1364-1371

DOI: https://doi.org/10.5114/aoms.2019.90414

Copyright $\odot 2019$ Termedia \& Banach

\begin{abstract}
Introduction: Cisplatin is an antineoplastic agent, which is thought to act on tissues with increased levels of reactive oxygen species and decreased levels of antioxidants. Pycnogenol is a potent antioxidant that is used in medical conditions caused by oxidative stress. The aim of our study is to demonstrate the effects of pycnogenol on cisplatin-induced uterine and ovarian damage in rats.

Material and methods: Wistar albino female rats were randomly divided into 3 groups before the experiment as follows: a $2.5 \mathrm{mg} / \mathrm{kg}$ cisplatin group (CG; $n=10$ ), a $40 \mathrm{mg} / \mathrm{kg}$ pycnogenol $+2.5 \mathrm{mg} / \mathrm{kg}$ cisplatin group (PCG; $n=10)$, and a healthy control group (HG; $n=10)$. Then, the ovaries and uteri of the rats were examined to determine malondialdehyde (MDA), total glutathione (tGSH) and superoxide dismutase (SOD) biochemical levels and the histopathological findings.

Results: Our study demonstrated that, in uterine and ovarian tissues of rats administered with cisplatin, there was a decrease in the levels of TGSH and SOD, while MDA was increased; however, it was observed that these ratios were reversed in the PCG group $(p<0.05)$. The number of follicles in the ovarian tissues was examined in all 3 groups. When the CG group was compared with the other two groups, the number of primordial, developing and atretic follicles was low, but there was no difference in the corpus luteum count.

Conclusions: Pycnogenol pretreatment alleviates cisplatin-induced uterine and ovarian injury in rats because of its antioxidative effect.
\end{abstract}

Key words: cisplatin, ovary, oxidative stress, pycnogenol, rat, uterus.

\section{Introduction}

Cisplatin (CP), a derivative of platinum, is widely used for the medical treatment of some kinds of human cancers, such as breast, endometrial and ovarian cancer [1]. Antineoplastic drugs such as CP, particularly

\author{
Corresponding author: \\ Asist. Prof. Can Turkler \\ Department of Gynecology \\ and Obstetrics \\ Faculty of Medicine \\ Erzincan Binali \\ Yıldırım University \\ Erzincan, Turkey \\ E-mail: dr_canturkler@yahoo. \\ com
}


those used during the reproductive period, may cause ovarian problems and infertility [2]. It has been shown that CP-related sterility is caused by the toxic impact of this chemotherapeutic agent on the primordial follicles. The toxic effects induced by CP are associated with an increased level of reactive oxygen species (ROS) and free radicals. This situation leads to lipoperoxidation and oxidative stress [3]. Also it has been shown that CP-induced infertility is related to oxidative stress in the ovary [4].

Pycnogenol is the name for a native herb extract from the bark of a French maritime pine (Pinus pinaster). It is a kind of extract that is composed of a mix of antioxidant flavonoids. It contains procyanidins, taxifolin, catechin and phenolic acids. Previous studies indicated that pycnogenol has great antioxidant potential as well as other bioactivities, such as decreasing enzyme activity and controlling gene expression [5]. The antioxidant capacity of pycnogenol is attributed to its high procyanidin content.

While pycnogenol supplementation has minimal side effects [6], it has beneficial effects on endothelial and vascular functions as well as cognitive abilities [5-7]. It has been shown that pycnogenol is a hepatoprotective molecule which has potential anti-inflammatory properties in some chronic diseases [8, 9]. Pycnogenol also inhibits histamine and proinflammatory cytokines and reduces allergic responses [10]. Icel et al. reported that pycnogenol treatment was highly effective in preventing cisplatin-induced oxidative stress in ocular and optic nerve tissues [11].

Investigations into the mechanism of the toxic effects of CP on organs and tissues suggest that antioxidants may be useful in reducing CP toxicity. This information suggests that pycnogenol may be effective in suppressing CP-induced uterine and ovarian toxicity. There is no study about the effect of pycnogenol on uterine and ovarian CP-induced injury in published literature. Therefore, the target of our experiment is to investigate the effect of pycnogenol on uterine and ovarian CP-induced injury in rats through a study of biochemical and histopathological evaluations.

\section{Material and methods}

\section{Animals}

The recommendations of the "ARRIVE guidelines" for animal care were taken into consideration. A total of thirty Wistar albino female rats weighing between 245 and 250 g were randomly chosen for use in the study. The rats were fed and housed at normal room temperature (22 to $24^{\circ} \mathrm{C}$ ) prior to the test. This study was carried out in accordance with international guidelines on the ethical use of animals (Ethics Committee Date and Number: 28.06.2018-7/151).

\section{Experimental groups}

Rats were randomly divided into 3 groups before the experiment as follows: a $2.5 \mathrm{mg} / \mathrm{kg}$ cisplatin group (CG; $n=10$ ), a $40 \mathrm{mg} / \mathrm{kg}$ pycnogenol + $2.5 \mathrm{mg} / \mathrm{kg}$ cisplatin group (PCG; $n=10$ ), and a healthy control group (HG; $n=10)$.

\section{Chemical substances}

The cisplatin (Ebewe) used in the study was provided by Liba (Turkey); thiopental sodium was provided by Ibrahim Etem Ulagay (Turkey) and pycnogenol was provided by Solgar (USA).

\section{Experimental procedure}

Pycnogenol was administered to the rats in the PCG group by oral gavage at a dose of $40 \mathrm{mg} / \mathrm{kg}$ because pycnogenol has been shown to be effective in animals at doses ranging from 10 to $40 \mathrm{mg} / \mathrm{kg}$ in published literature $[12,13]$. At the same time, the same volume of distilled water was applied to the CG and HG rat groups by an oral route. One hour after administration of the pycnogenol and distilled water, the rats were injected with $C P$ at a dosage of $2.5 \mathrm{mg} / \mathrm{kg}$ intraperitoneally (i.p.) - except for the HG group, because this dose of CP was the mean effective dose to create oxidative stress in rats [11]. Pycnogenol, cisplatin, and distilled water were applied at the indicated dose and volume once a day for 14 days using the same method. In published literature, the drugs that protect against CP toxicity are usually given to experimental animals one hour before the CP [14]. At the end of the study, ten rats from each group were euthanized using $50 \mathrm{mg} / \mathrm{kg}$ of thiopental sodium given intraperitoneally. Their uterine and ovarian tissues were removed, and the malondialdehyde (MDA), total glutathione (tGSH), and superoxide dismutase (SOD) levels were measured. Oxidant and antioxidant parameters were measured to evaluate oxidative stress in both types of tissue. The tissues were also examined histopathologically. The biochemical and histopathological results were compared between the 3 groups.

\section{Biochemical analysis of uterine and ovarian tissues}

All the uterine and ovarian tissues were weighed and homogenized on ice with $2 \mathrm{ml}$ of the relevant buffer. The buffers were $0.5 \%$ hexadecyltrimethyl ammonium bromide ( $\mathrm{pH} 6), 1.15 \%$ $\mathrm{KCl}$ (potassium chloride) solution for the MDA analysis, and a pH 7.5 $\mathrm{PO}_{4}{ }^{3-}$ (phosphate) buffer for the other analyses. After that, they were centri- 
fuged for $15 \mathrm{~min}$. The supernatant was used to measure oxidant and antioxidant parameters. The levels of MDA (Cat. No: 10009055), tGSH (Cat. No: 703002) and SOD (Cat. No: 706002) were measured according to the commercial kit supplied by Cayman Chemical, Ltd., ELISA kit, USA.

\section{Measurement of malondialdehyde}

The levels of tissue lipid peroxidation were detected by predicting MDA using the thiobarbituric acid test through using spectrophotometric measurement at a wavelength of $532 \mathrm{~nm}$ according to Ohkawa et al. [15]. The results were expressed as micromol/g of protein.

\section{Measurement of total glutathione}

The level of tGSH in the tissues was detected according to the method described by Sedlak and Lindsay [16]. The homogenate was used to detect GSH using 5,5'-dithiobis (2-nitrobenzoic acid). The absorbance was measured using a spectrophotometer at a wavelength of $412 \mathrm{~nm}$. The results were expressed as nanomol/g of protein.

\section{Measurement of superoxide dismutase activity}

Measurement of the SOD activity was performed according to the method described by Sun et al. [17]. SOD is a product of uric acid metabolism, which is controlled by xanthine oxidase. Superoxide dismutase reacts with nitro blue tetrazolium (NBT) to produce a purple-colored formazan dye. The absorbance of the formazan was measured at a wavelength of $560 \mathrm{~nm}$ using a spectrophotometer. The results were expressed as U/g of protein.

\section{Histopathological analysis}

Uterine and ovarian tissue samples were first treated with $10 \%$ formaldehyde for microscopic examination. Following this, the tissue samples were washed under tap water for 1 day. The tis- sue samples were then treated with a conventional grade of alcohol to remove the water. Samples were then passed through xylol and embedded in paraffin. Four to five micron sections were then cut from the paraffin blocks and colored with hematoxylin-eosin. All photographic images were taken using an Olympus DP2-SAL firmware program (Olympus Inc. Tokyo, Japan) assessment. Histopathological examination was carried out by a blind reading of the histology.

\section{Statistical analysis}

SPSS software 22.0 was employed for the statistical analysis (SPSS Inc., Chicago, IL). Mean and standard deviation descriptive statistical methods were obtained. Differences among the three groups were evaluated by Tukey analysis. A level of $p<0.05$ was considered as statistically significant.

\section{Results}

As seen in Table I (for ovarian tissues), when compared to the HG group, the increase in MDA in the CG group was significant $(p<0.05)$. A $40 \mathrm{mg} / \mathrm{kg}$ pycnogenol dose diminished the amount of MDA compared to the CG group ( $p<0.05)$. The $2.5 \mathrm{mg} / \mathrm{kg}$ cisplatin dose decreased the tGSH level in the ovaries of the rats compared to the $\mathrm{HG}$ group $(p<0.05)$. The $40 \mathrm{mg} / \mathrm{kg}$ pycnogenol dose increased the tGSH level in the PCG group compared to the CG group $(p<0.05)$. The SOD level was significantly suppressed in the CG group in comparison to the HG group ( $p<0.05)$, but a significant rise was seen in the PCG group compared to the CG group $(p<0.05)$.

As seen in Table I (for uterine tissues), when compared to the HG group, the increase in MDA in the CG group was significant $(p<0.05)$. A $40 \mathrm{mg} / \mathrm{kg}$ dose of pycnogenol diminished the amount of MDA compared to the CG group ( $p<0.05$ ). The $2.5 \mathrm{mg} / \mathrm{kg}$ cisplatin decreased the tGSH level in the uterus of rats compared to the HG group

Table I. Biochemical results of ovarian and uterine tissues for the three groups

\begin{tabular}{|c|c|c|c|c|c|c|}
\hline Tissue & HG $(n=10)$ & CG $(n=10)$ & PCG $(n=10)$ & P1 & P2 & P3 \\
\hline MDA (ovary) & $5.3 \pm 0.5$ & $16.9 \pm 2.5$ & $6.5 \pm 0.7$ & 0.001 & 0.220 & 0.001 \\
\hline tGSH (ovary) & $6.8 \pm 0.6$ & $2.5 \pm 0.4$ & $5.9 \pm 0.6$ & 0.001 & 0.006 & 0.001 \\
\hline SOD (ovary) & $11.3 \pm 1.5$ & $3.9 \pm 0.5$ & $9.0 \pm 0.6$ & 0.001 & 0.001 & 0.001 \\
\hline MDA (uterus) & $7.9 \pm 0.6$ & $22.9 \pm 2.2$ & $6.1 \pm 0.3$ & 0.001 & 0.017 & 0.001 \\
\hline tGSH (uterus) & $7.5 \pm 0.9$ & $1.8 \pm 0.5$ & $3.6 \pm 0.3$ & 0.001 & 0.001 & 0.001 \\
\hline SOD (uterus) & $11.3 \pm 1.5$ & $1.9 \pm 0.4$ & $9.0 \pm 0.6$ & 0.001 & 0.001 & 0.001 \\
\hline
\end{tabular}

dialdehyde, $t G S H$ - total glutathione, $S O D$ - superoxide dismutase. 
( $p<0.05$ ). A $40 \mathrm{mg} / \mathrm{kg}$ pycnogenol dose increased the tGSH level in the PCG group when compared to the CG group $(p<0.05)$. The SOD level was significantly suppressed in the CG group compared to the HG group $(p<0.05)$, but a significant rise was seen in the PCG group compared to the CG group $(p<0.05)$.

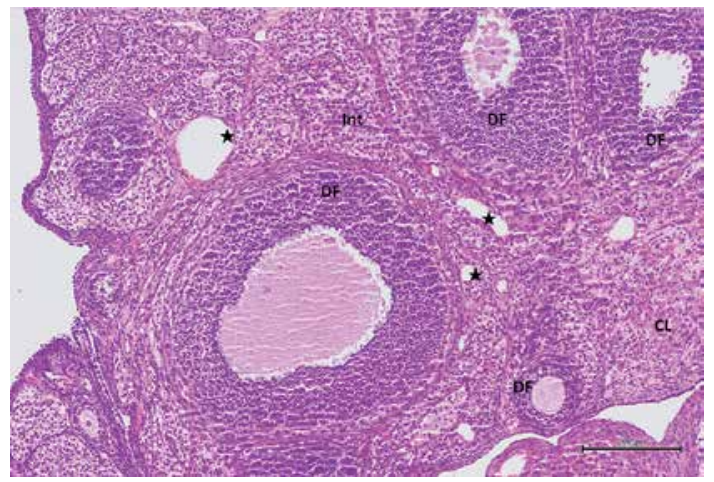

Figure 1. Hematoxylin-eosin staining in ovarian tissue in the control group

DF - developing follicule, Int - intersititial area, CL - corpus luteum, *blood vessel (100x)

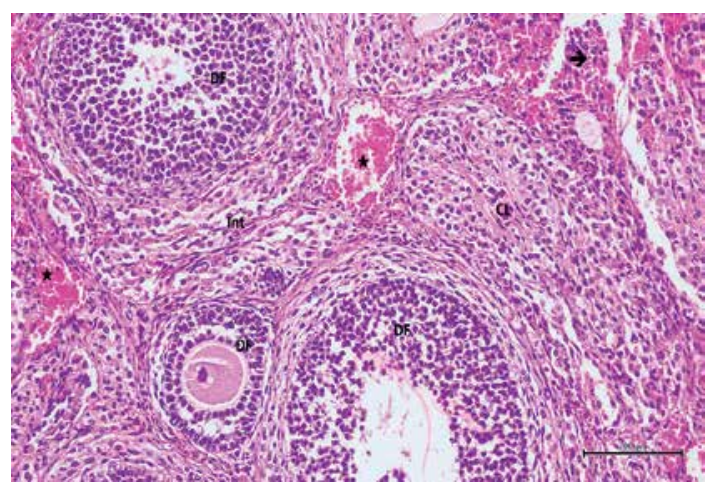

Figure 3. Hematoxylin-eosin staining in ovarian tissue in the cisplatin group

DF - degenerated developing follicule, Int - intersititial edema, *congested blood vessel, CL - corpus luteum, $\rightarrow$ hemorrhage (200x)

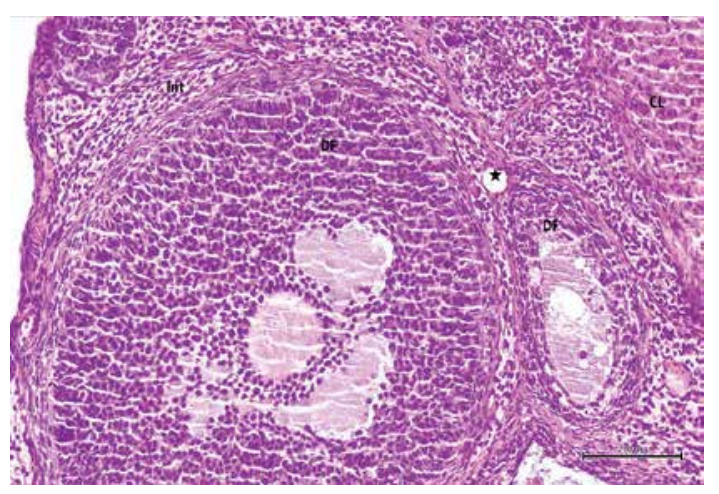

Figure 5. Hematoxylin-eosin staining in ovarian tissue in the cisplatin + pycnogenol group

$D F$ - developing follicule, Int - intersititial area, CL - corpus luteum, *blood vessel (200x)
Histological examination of ovaries in the control group revealed that the developing ovarian follicles, the interstitial areas between them, the blood vessels in the cortex and medulla, the corpus luteum, and the luteal and follicular cells all appeared normal (Figure 1). Figures 2 and 3 show that ovarian tissues in the cisplatin

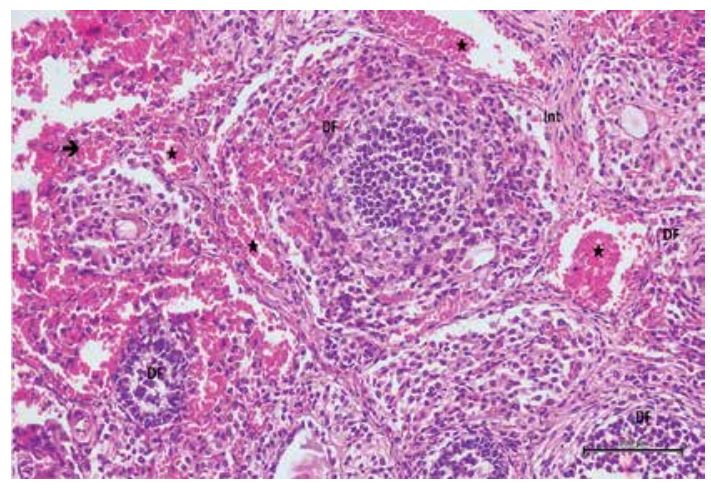

Figure 2. Hematoxylin-eosin staining in ovarian tissue in the cisplatin group

DF- degenerated developing follicule, Int - intersititial ede$\mathrm{ma}$, *dilatated and congested blood vessel, $\rightarrow$ hemorrhage (200x)

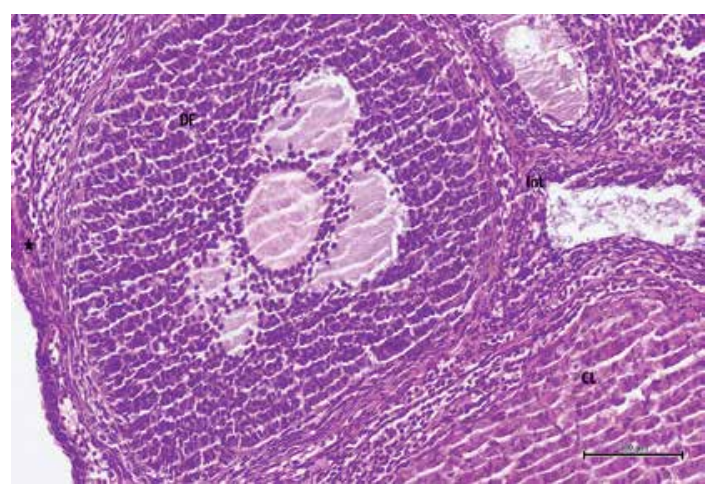

Figure 4. Hematoxylin-eosin staining in ovarian tissue in the cisplatin + pycnogenol group

DF - developing follicule, Int - intersititial area, CL - corpus luteum, *blood vessel (200x)

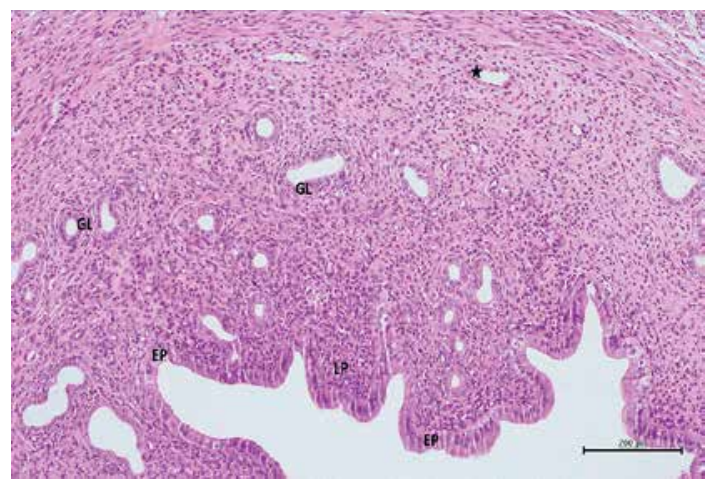

Figure 6. Hematoxylin-eosin staining in uterine tissue in the control group

EP - epithelium, $L P$ - lamina propria, $G L$ - uterine gland, *blood vessel (100x) 
group showed degenerative changes, including developing follicular regression, vascular dilation and congestion, hemorrhage, interstitial edema, luteal and follicular cell degeneration, and pericellular edema. In rats treated with pycnogenol prior to cisplatin, the appearance of the cortex and medulla was revealed to be normal, there was mild vascular congestion, normal follicular and luteal cells, a normal follicular structure and an increased number of developing follicles when compared to the group exposed to cisplatin (Figures 4 and 5).

In addition, the number of follicles in the ovarian tissues was examined in all 3 groups. Primordial follicles, developing follicles, atretic follicles and the corpus luteum were all counted. When the CG group was compared with the other two groups, the number of primordial, developing and atretic follicles was low, but there was no difference in the corpus luteum count (Table II).

When the uterine tissue was examined, the uterine mucosa looked normal but included a chaotically shaped uterine lumen lined by a simple cuboidal epithelium (Figure 6). In the cisplatin group, there were some differences in the luminal epithelial cells that resulted in a columnar appearance and a highly degenerated shape. There was intense pericellular edema in the glands. In addition, vascular dilation and congestion in the mu- cosa were observed, along with inflammatory infiltration (Figures 7 and 8). In the rats with uterine tissues treated with pycnogenol prior to cisplatin, sections showed mild pericellular edema, a simple cuboidal uterine epithelium, and decreased congestion and inflammatory infiltration (Figures 9 and 10).

Histopathological evaluation was performed in ten subjects for each group. One center and five peripheral areas of each sample were examined for histopathological evaluation. The degeneration criteria intensity was graded semiquantitatively and determined to be $0,1,2$, or 3 (normal, weak, moderate or strong). The histopathological scoring results are given in Table III.

\section{Discussion}

The aim of our study was to show, for the first time, the effects of pycnogenol in preventing CP-induced uterine and ovarian damage. We showed that pycnogenol has alleviating effects on oxidative stress and inflammation related to CP.

Antineoplastic drugs, such as CP, have many side effects including ovarian problems and infertility. Genital organ damage because of chemotherapy is the main problem for young women [18]. However, we showed that the number of primordial, developing and atretic follicles was low for the CP-induced group. This situation ex-

Table II. Comparison of study groups according to the follicle counts

\begin{tabular}{|lcccccc|}
\hline Follicles & HG $(n=10)$ & CG $(n=10)$ & PCG $(n=10)$ & P1 & P2 & P3 \\
\hline PF & $13.3 \pm 1.2$ & $6.0 \pm 0.9$ & $13.1 \pm 1.1$ & 0.001 & 0.958 & 0.001 \\
\hline DF & $23.3 \pm 2.2$ & $12.5 \pm 2.1$ & $23.1 \pm 1.9$ & 0.001 & 0.957 & 0.001 \\
\hline AF & $3.3 \pm 1.1$ & $1.1 \pm 0.9$ & $3.2 \pm 0.9$ & 0.002 & 0.999 & 0.002 \\
\hline CL & $13.5 \pm 1.9$ & $13.6 \pm 1.7$ & $13.5 \pm 1.5$ & 0.953 & 0.999 & 0.953 \\
\hline
\end{tabular}

P1 - comparison of HG and CG groups, P2 - comparison of HG and PCG groups, P3 - comparison of CG and PCG groups. PF - primordial follicles, $D F-$ developing follicles, $A F-$ atretic follicles, $C L$ - corpus luteum.

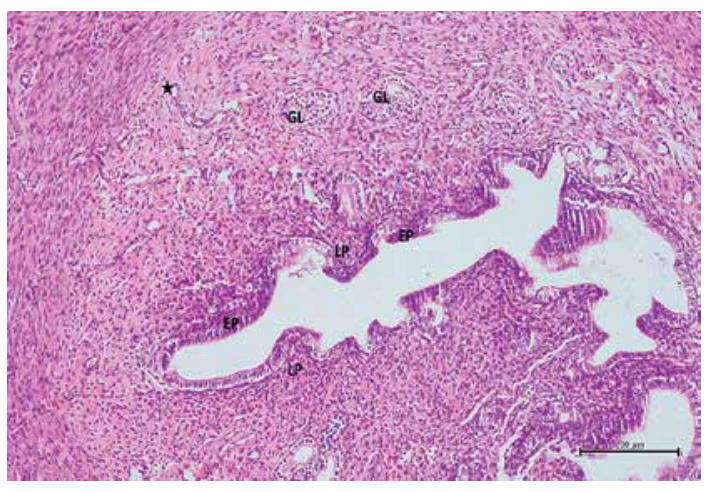

Figure 7. Hematoxylin-eosin staining in uterine tissue in the cisplatin group

$E P$ - degeneration in epithelium, $L P$ - lamina propria, $G L$ - pericellular edema in uterine gland, *dilatated and congested blood vessel (100x)

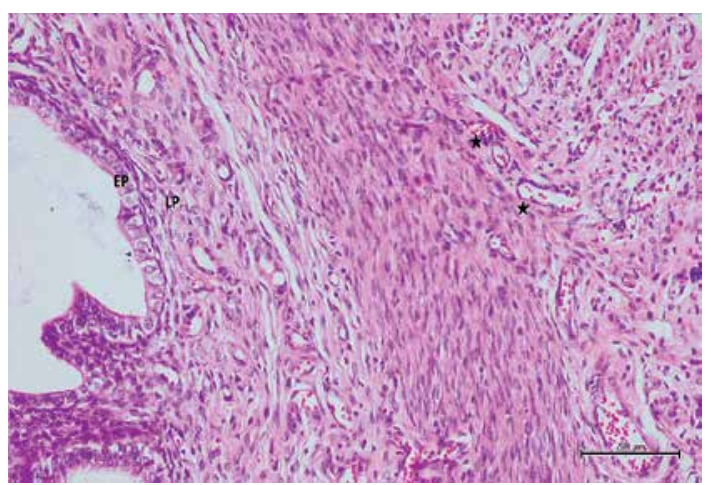

Figure 8. Hematoxylin-eosin staining in uterine tissue in the cisplatin group

$E P$ - degeneration in epithelium, LP - lamina propria, *dilatated and congested blood vessel (100x) 


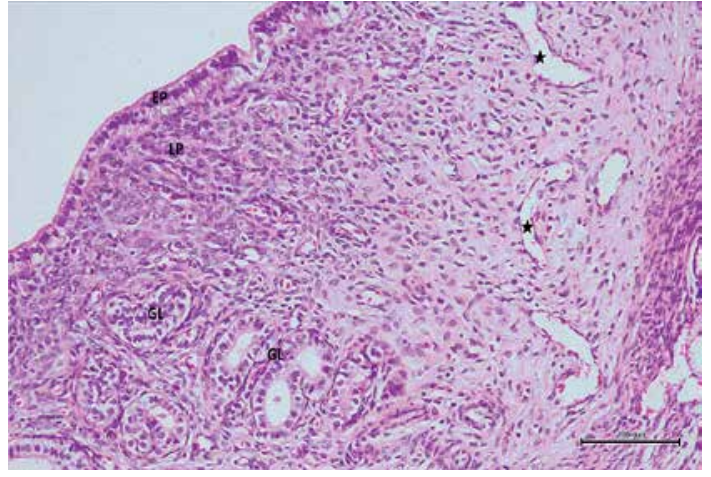

Figure 9. Hematoxylin-eosin staining in uterine tissue in the cisplatin + pycnogenol group

EP-epithelium, LP-lamina propria, $G L$ - mild pericellular edema in uterine gland, *decreased congestion in blood vessel (200x)

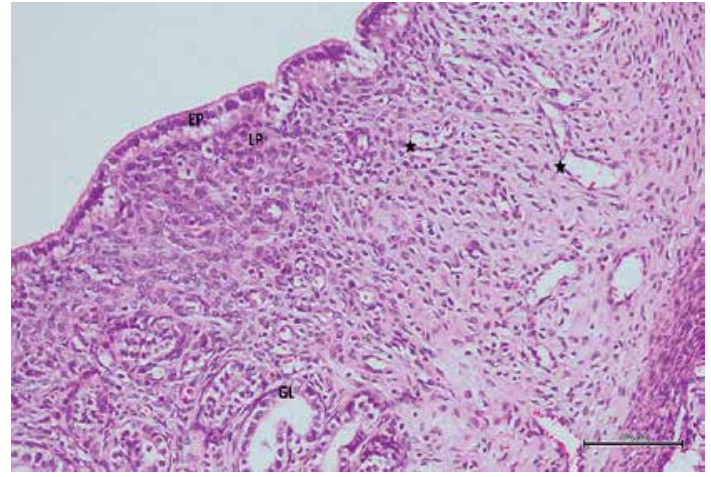

Figure 10. Hematoxylin-eosin staining in uterine tissue in the cisplatin + pycnogenol group

EP-epithelium, LP-lamina propria, GL-mild pericellular edema in uterine gland, *decreased congestion in blood vessel (200x)

Table III. Histopathological scoring results of ovarian and uterine tissues for the three groups

\begin{tabular}{|lcccc|}
\hline Tissue & HG $(n=10)$ & CG $(n=10)$ & PCG $(n=10)$ & $P$-value \\
\hline \begin{tabular}{l} 
Ovary: \\
\hline Cell degeneration
\end{tabular} & 0 & $2.77 \pm 0.61$ & $0.86 \pm 0.50$ & $<0.001$ \\
\hline Vascular dilation & 0 & $2.36 \pm 0.78$ & $0.63 \pm 0.54$ & $<0.001$ \\
\hline Vascular congestion & 0 & $2.63 \pm 0.92$ & $1.41 \pm 0.48$ & $<0.001$ \\
\hline Hemorrhage & 0 & $2.69 \pm 0.83$ & $0.44 \pm 0.65$ & $<0.001$ \\
\hline Edema & 0 & $2.44 \pm 0.76$ & $0.38 \pm 0.67$ & $<0.001$ \\
\hline \begin{tabular}{l} 
Uterus: \\
\hline Pericellular edema
\end{tabular} & 0 & $2.72 \pm 0.72$ & $1.19 \pm 0.66$ & $<0.001$ \\
\hline Inflammation & 0 & $2.50 \pm 0.75$ & $1.38 \pm 0.37$ & $<0.001$ \\
\hline Vascular dilation & 0 & $2.61 \pm 0.66$ & $1.25 \pm 0.27$ & $<0.001$ \\
\hline Vascular congestion & 0 & $2.69 \pm 0.60$ & $1.30 \pm 0.22$ & $<0.001$ \\
\hline
\end{tabular}

plains the mechanism for ovarian failure and early menopause development in patients receiving chemotherapy.

There are countless experimental studies about pycnogenol. In this literature, the antioxidative effects of pycnogenol have been investigated in various organs and tissues, such as the eye, brain, optic nerve, nasal mucosa, peritoneum, lymph nodes, bones, heart, aorta, kidney, liver and colon in animal models [8, 10-13, 19-24]. This literature information suggests that antioxidant drugs might be beneficial in preventing CP-related uterine and ovarian toxicity.

The deterioration in the equilibrium between the oxidants and antioxidants in favor of the oxidants is known as oxidative stress [25]. ROS damage the tissues, especially through lipid peroxidation [26]. The peroxidation of lipids in cell membranes can lead to the formation of MDA, which is a toxic product. GSH and SOD are protective enzymes against ROS. Borekcl et al. stated that CP-induced oxidative damage in ovarian tissues increases the MDA concentration and decreases the GSH concentration [4]. Yilmaz et al. declared that the cytotoxic effects of cyclophosphamide, which is a chemotherapeutic agent, on the uterus can be prevented by natural antioxidant preparations (curcumin and capsaicin) [27]. Kaygusuzoglu et al. suggested that the suppression of oxidative stress and the inflammatory response with an antioxidant (zingerone) could be a successful tactic in the treatment of CP-induced ovarian follicle and uterine damage [28]. These studies suggest that oxidative tissue damage caused by chemotherapy can be prevented by the administration of antioxidant molecules such as pycnogenol.

According to the results of our experiment, in the uterine and ovarian tissues of animals treated 
with CP, there were rising amounts of MDA, which is an oxidant parameter, while the amounts of antioxidants, such as SOD and tGSH, were decreased. Pycnogenol reduced the level of MDA significantly compared to the CG group ( $p<0.05)$. In addition, pycnogenol significantly increased the tGSH and SOD levels in the PCG group compared to the CG group $(p<0.05)$.

The histopathological results of our study were similar to previous studies, and showed the alleviating effect of pycnogenol on CP-induced oxidative stress in the uterine and ovarian tissues at the cell level. When we compared the HG and PCG groups histopathologically, primordial, developing and atretic follicle numbers were similar. This showed us that the decrease in the number of oocytes caused by chemotherapy can be prevented by the alleviating effects of pycnogenol.

The fact that malignant diseases are increasingly seen in young age groups has led to an increase in the number of medical interventions to protect fertility before surgery and chemotherapy. The most important and popular fertility preservation method is mature oocyte cryopreservation [29]. As the importance of antioxidant molecules is understood in recent years, perhaps these methods will lose their importance, and the fertility of the patients can be maintained without the need for oocyte cryopreservation.

There are some restrictions of our experiment. Firstly, there is no previous information about the effect of pycnogenol on CP-induced uterine and ovarian injury. Secondly, as the aim of the study was to investigate whether pycnogenol had alleviating effects on CP-induced uterine and ovarian injury, only a single dose of $40 \mathrm{mg} / \mathrm{kg}$ was used. It may be better to compare different doses of pycnogenol to discover the mean effective dose. Thirdly, CP-induced uterine and ovarian injury was demonstrated by the histopathological modifications in both tissues. This damage must be evaluated by apoptosis or infarct size with other studies. Fourthly, the results of experimental studies on animals may not be extrapolated to humans. We think that more accurate information will be obtained in the future if more studies on this subject are performed.

In conclusion, pycnogenol pretreatment alleviates cisplatin-induced uterine and ovarian injury in rats, probably because of its antioxidative effect. Antioxidant molecules such as pycnogenol may help prevent the damage caused by chemotherapy to genital organs in young women.

\section{Acknowledgments}

We thank Professor Halis Suleyman of the Department of Pharmacology, Faculty of Medicine, Erzincan Binali Yıldırım University for his technical support and suggestions.

\section{Conflict of interest}

The authors declare no conflict of interest.

\section{References}

1. Liu HN, Qie P, Yang G, Song YB. miR-181b inhibits chemoresistance in cisplatin-resistant $\mathrm{H} 446$ small cell lung cancer cells by targeting Bcl-2. Arch Med Sci 2018; 14: 745-51.

2. Sonmezer M, Oktay K. Fertility preservation in female patients. Hum Reprod Update 2004; 10: 251-66.

3. Meng $X$, Chen $H$, Wang G, et al. Hydrogen-rich saline attenuates chemotherapy-induced ovarian injury via regulation of oxidative stress. Exp Ther Med 2015; 10 : 2277-82.

4. Borekcı B, Yapca OE, Turan MI, et al. Prevention of ovarian oxidative stress-related infertility associated with cisplatin in rats with thiamine pyrophosphate. Lat Am J Pharm 2013; 32: 512-7.

5. Packer L, Rimbach G, Virgili F. Antioxidant activity and biologic properties of a procyanidin-rich extract from pine (Pinus maritima) bark, pycnogenol. Free Radic Biol Med 1999; 27: 704-24.

6. Grimm T, Schäfer A, Högger P. Antioxidant activity and inhibition of matrix metalloproteinases by metabolites of maritime pine bark extract (pycnogenol). Free Radic Biol Med 2004; 36: 811-22.

7. Maimoona A, Naeem I, Saddige Z, et al. A review on biological, nutraceutical and clinical aspects of French maritime pine bark extract. J Ethnopharmacol 2011; 133: 261-77.

8. Mei L, Mochizuki M, Hasegawa N. Hepatoprotective effects of pycnogenol in a rat model of non-alcoholic steatohepatitis. Phytother Res 2012; 26: 1572-4.

9. Taner G, Aydın S, Aytaç Z, et al. Assessment of the cytotoxic, genotoxic, and antigenotoxic potential of Pycnogenol ${ }^{\oplus}$ in in vitro mammalian cells. Food Chem Toxicol 2013; 61: 203-8.

10. Günel C, Demirci B, Eryılmaz A, et al. Inhibitory effect of Pycnogeno ${ }^{\oplus}$ on airway inflammation in ovalbumin-induced allergic rhinitis. Balkan Med J 2016; 33: 620-6.

11. Icel E, Uçak T, Agcayazi B, et al. Effects of Pycnogenol on cisplatin induced optic nerve injury: an experimental study. Cutan Ocul Toxicol 2018; 37: 396-400.

12. Huang G, Wu J, Wang S, et al. Pycnogenol( $\left({ }^{\circledR}\right)$ treatment inhibits bone mineral density loss and trabecular deterioration in ovariectomized rats. Int J Clin Exp Med 2015; 8: 10893-901.

13. Lee IC, Ko JW, Park SH, et al. Ameliorative effects of pine bark extract on cisplatin-induced acute kidney injury in rats. Ren Fail 2017; 39: 363-71.

14. Coskun R, Turan MI, Turan IS, et al. The protective effect of thiamine pyrophosphate, but not thiamine, against cardiotoxicity induced with cisplatin in rats. Drug Chem Toxicol 2014; 37: 290-4

15. Ohkawa H, Ohishi N, Yagi K. Assay for lipid peroxides in animal tissues by thiobarbituric acid reaction. Anal Biochem 1979; 95: 351-8.

16. Sedlak J, Lindsay RH. Estimation of total, protein-bound, and nonprotein sulfhydryl groups in tissue with Ellman's reagent. Anal Biochem 1968; 25: 192-205.

17. Sun Y, Oberley LW, Li Y. A simple method for clinical assay of superoxide dismutase. Clin Chem 1988; 34: 497-500.

18. Morgan S, Anderson RA, Gourley C, et al. How do chemotherapeutic agents damage the ovary? Hum Reprod Update 2012; 18: 525-35. 
19. Scheff SW, Roberts KN. Cognitive assessment of pycnogenol therapy following traumatic brain injury. Neurosci Lett 2016; 634: 126-31.

20. Goret CC, Goret NE, Kiraz A, et al. The effect of pycnogenol on lymphatic nodes and adhesion during in a peritoneal adhesion model in rats. Acta Cir Bras 2018; 33: 134-43.

21. Sahbaz A, Aynioglu O, Isik H, et al. Pycnogenol prevents peritoneal adhesions. Arch Gynecol Obstet 2015; 292: 1279-84.

22. Unsal AIA, Kocaturk T, Gunel C, et al. Effect of Pycnogenol $^{\circledR}$ on an experimental rat model of allergic conjunctivitis. Graefes Arch Clin Exp Ophthalmol 2018; 256: 1299-304.

23. Liu R, Fan B, Cong H, et al. Pycnogenol reduces toll-like receptor 4 signaling pathway-mediated atherosclerosis formation in apolipoprotein E-deficient mice. J Cardiovasc Pharmacol 2016; 68: 292-303.

24. Değer KC, Şeker A, Özer I, et al. The effects of Pycnogenol( $\left({ }^{(}\right)$on colon anastomotic healing in rats given preoperative irradiation. Int J Surg 2013; 11: 983-8.

25. Altuner D, Gulaboglu M, Yapca OE, et al. The effect of mirtazapine on cisplatin-induced oxidative damage and infertility in rat ovaries. Sci World J 2013; 22: 327240.

26. Trocha M, Merwid-Ląd A, Pieśniewska M, et al. Agerelated differences in function and structure of rat livers subjected to ischemia/reperfusion. Arch Med Sci 2018; 14: 388-95.

27. Yilmaz E, Melekoglu R, Ciftci O, et al. The therapeutic effects of curcumin and capsaicin against cyclophosphamide side effects on the uterus in rats. Acta Cir Bras 2018; 33: 499-507.

28. Kaygusuzoglu E, Caglayan C, Kandemir FM, et al. Zingerone ameliorates cisplatin induced ovarian and uterine toxicity via suppression of sexhormone imbalances, oxidative stress, inflammation and apoptosis in female Wistar rats. Biomed Pharmacother 2018; 102: 517-30.

29. Liang T, Motan T. Mature oocyte cryopreservation fo fertility preservation. Adv Exp Med Biol 2016; 951: 155-61. 